\title{
Modelling for Forest Fire Evolution Based on the Energy Accumulation and Release
}

\author{
Fan Yang \\ College of Computer \\ Hubei University of Education \\ Wuhan, China
}

\author{
Qing Yang *, Xingxing Liu \\ School of Management \\ Wuhan University of Technology \\ Wuhan, China
}

\author{
Pan Wang* \\ Institute of Systems Science and \\ Engineering \\ Wuhan University of Technology \\ Wuhan, China
}

\begin{abstract}
Forest fire evolution plays an important role in the decision-making of controlling the forest fire. This paper aims to simulate the dynamics of the forest fire spread using a cellular automaton approach. Having analyzed the characteristics and evolution of forest fires, a simulation model for the forest fire evolution based on the energy accumulation and release is proposed. And, taking Australia's catastrophic forest fire in 2009 as an example, the fire's evolution closely to the reality is simulated. The results of the experiments are shown that if forest energy is released in a small scale before or during the fire, the fire would be better controlled even if it does not occur. Improving the efficiency of the fire extinguishing procedures and reducing the speed of the fire spread are also effective for controlling the forest fire.
\end{abstract}

Keywords-forest fire evolution; energy accumulation and release; cellular automaton $(\mathrm{CA})$; simulation

\section{INTRODUCTION}

This Development over the millennia have left the world in a grave state and it faces both complex and greater contemporary challenges. Therefore forest fire management is a subject that is worthy of investigation. A forest fire system is complicated and involves nature, society and economic development. Research on forest fire control mainly focuses upon forest fire evolution models and risk reduction following disaster.

The classical evolution model of forest fires proposed by Drossel and Scwhabl, is a type of cellular automata (CA) model, which simulates the growth of trees, the occurrence and extension of the fire and other processes with certain rules [1]. Based on the classical model, other more specific CA models [2-6] that have been introduced mostly change the system's conditions, such as the immune forest fire model [2], the limited scale effects of forest fires model [4], the integer type of forest fire model [5] and the heterogeneity of forest fire model [6].

Encinas et al. [7] proposed a hexagonal CA model for the forest fire evolution and discussed the impact of this six-edged structure on the forest fires spreading. Having considered the geological characteristics and hazard factors of fires, Yassemia et al. [8] proposed an integrated GIS-based CA model. Berjak et al. [9] presented a CA model that is capable of predicting the fire's spread in spatially heterogeneous Savanna systems. The physical basis of Rothermel's fire spread model (1972) was modified to a spatial context and used to improve the CA model introduced by Karafyllidis and Thanailakis (1997). Alexandridis et al. [10] presented and illustrated the simulation results of a CA model, thereby describing the dynamics of the spread of a forest fire on a mountainous landscape; having taken into account factors such as the type and density of vegetation, the wind speed and direction and how quickly the fire is spotted. Hui et al. [11] proposed a multi-state probability CA model of forest fires, which analyzed changes in the occupancy of forest trees under two sets of conditions; one being that they exist in spaces with no growth and are not susceptible to fires, the other being that the trees differ from their neighborhood due to deforestation. Through the improvement of CA probability, it is possible to stimulate the occurrence mechanism of forest fires. Subsequently conclusions were drawn that the correct type of spacing between trees and modest felling can prevent the spread of fires and realize effective tree growth.

In order to study the whole developing tendency and the evolvement rules of the forest fire system, Guangjun and Yaodong [12] introduced a pattern-oriented model based on an agent and proposed an agent-based forest fire simulating model. Furthermore their computer simulation was implemented by integrating the harmonizing nature and microscopic mechanism of society. Qinggui et al. [13] put forward a simple model of forest fires based on the power distribution of forest fire models, which can effectively reveal its self-organized criticality. A "frequency-scale" distribution is obtained by a numerical stimulation and the model satisfies the limited size effects. The changes of the average burned area are provided by adjusting the control parameters. The authors discuss the differences in "frequency-scale" distribution between their model and the original one, after the introduction of heterogeneity and wind factors. The results from their model that show how to control forest fires provide a good verification of their proposal.

In summary, the existing research lacks a discussion of the energy of forests. In order to understand the evolution of the forest fire and propose related methods for its management, a new evolution model is presented in this paper based on energy accumulation and release. The energy accumulation of forests is inevitable, and experiments show that the energy released in a suitable time and by a suitable release ratio could clearly reduce the frequency of forest fires occurrence. The controlling of forest fires could be realized following repeated practical tests to establish the optimal energy release time and ratio.

\footnotetext{
*Corresponding authors..
} 


\section{THE CHARACTERISTICS OF FOREST FIRES AND MODEL FACTORS}

The common features of forest fires are continuous high temperatures and excessively strong winds that lead to the outbreak site of fire becoming out of control in a shorter time period, and eventually lead to large-scale fires in a large stricken area and the rapid spread of a fire, which can last for a few days or up to a month. Thus, the key elements of forest fires are taken as the important parameters for the model. The analogy between the features of forest fires and the model parameters is shown in Table 1.

TABLE I. THE CHARACTERISTICS OF ForEST FiRES AND THE MODEL PARAMETERS

\begin{tabular}{|l|l|}
\hline \multicolumn{1}{|c|}{ Real-world } & Modeling system \\
\hline \multicolumn{1}{|c|}{ The forest area } & The system space $M$ \\
\hline $\begin{array}{l}\text { Environmental factors: degree of drought } \\
\text { and wind speed }\end{array}$ & $\begin{array}{l}\text { Number } W \\
\text { accumulation and the transfer } \\
\text { rate }\end{array}$ \\
\hline Trees in one unit (the affected unit) & Agent $A_{i}$ \\
\hline $\begin{array}{l}\text { A state of the affected unit (latency, } \\
\text { burning, extinguishing, overburning) }\end{array}$ & A state of the agents \\
\hline $\begin{array}{l}\text { The longest sunshine duration } \\
\text { The sunshine duration of an affected unit } \\
\text { (sunlight exposure brings about the energy } \\
\text { accumulation) }\end{array}$ & $\begin{array}{l}\text { The length } L_{(\mathrm{A})} \text { of the agent } \\
\text { gene } N_{\text {(A) }}\end{array}$ \\
\hline $\begin{array}{l}\text { Time between the beginning and the end } \\
\text { of the forest fire in an affected unit } q \text { of } A_{i}\end{array}$ & Burning period of $A_{i}$ \\
\hline The burning speed of an affected unit & $\begin{array}{l}\text { Changes in positional value of } \\
N_{\text {(A) }}\end{array}$ \\
\hline $\begin{array}{l}\text { The fire spreading speed of an affected } \\
\text { unit }\end{array}$ & Spreading speed $m$ of $A_{i}$ \\
\hline The burning units & Total $R_{t}$ of burning agents \\
\hline Controlling measures for the forest fire & $\begin{array}{l}\text { The algorithm of controlling } \\
\text { agents }\end{array}$ \\
\hline $\begin{array}{l}\text { The efficiency of the fire extinguishing } \\
\text { procedures }\end{array}$ & $\begin{array}{l}\text { The efficiency of the fire } \\
\text { extinguishing } p_{m}\end{array}$ \\
\hline
\end{tabular}

Moreover, the evolution of individuals will lead to demands for the state changes of the system. The status that might be produced during the evolution of the modeling system resembles real-world events. A detailed description is shown in Table 2.

TABLE II. AN ANALYSIS OF STATE OF THE FOREST FIRE

\begin{tabular}{|l|l|}
\hline The state of the forest fire & Description in the model \\
\hline Beginning time & Time the evolution begins $(t=0)$ \\
\hline Explosion point & $\begin{array}{l}\text { Number of burning agents coming to a } \\
\text { peak }\left(t=t_{p}\right)\end{array}$ \\
\hline Expanding period & Period from $t=0$ to $t=t_{p}$ \\
\hline Declining period & $\begin{array}{l}\text { Period from explosion to stability of the } \\
\text { system }\end{array}$ \\
\hline Vanishing period & Recovery to the stable situation \\
\hline
\end{tabular}

\section{EVOLUTION MODEL}

According to the above analysis, the model is built based on CA algorithm. Assume that each two-dimensional cell stands for a unit of a forest where there are a variety of trees; moreover there is a random distribution of the energy value and the energy is accumulating over time. From the perspective of energy, treating energy accumulation as the general term of tree growth, the accumulation of leaves, persistent drought and other factors, are all closer to reality than simply considering planting trees in a blank space. Additionally, the aim of this model is not to predict a fire but to simulate its evolution and search for controlling measures. Furthermore, assume that the number of fire points is known, and the probability that the trees catch fire is determined by the energy accumulation and the degree of the combustion of the surrounding trees. The extinguishing efficiency $\left(p_{m}\right)$, fire spreading speed $(m)$ and other parameters, as well as the embedded energy release strategy algorithms, could all influence the simulation of the evolution of forest fires. The computational experimental process is shown in Figure1.

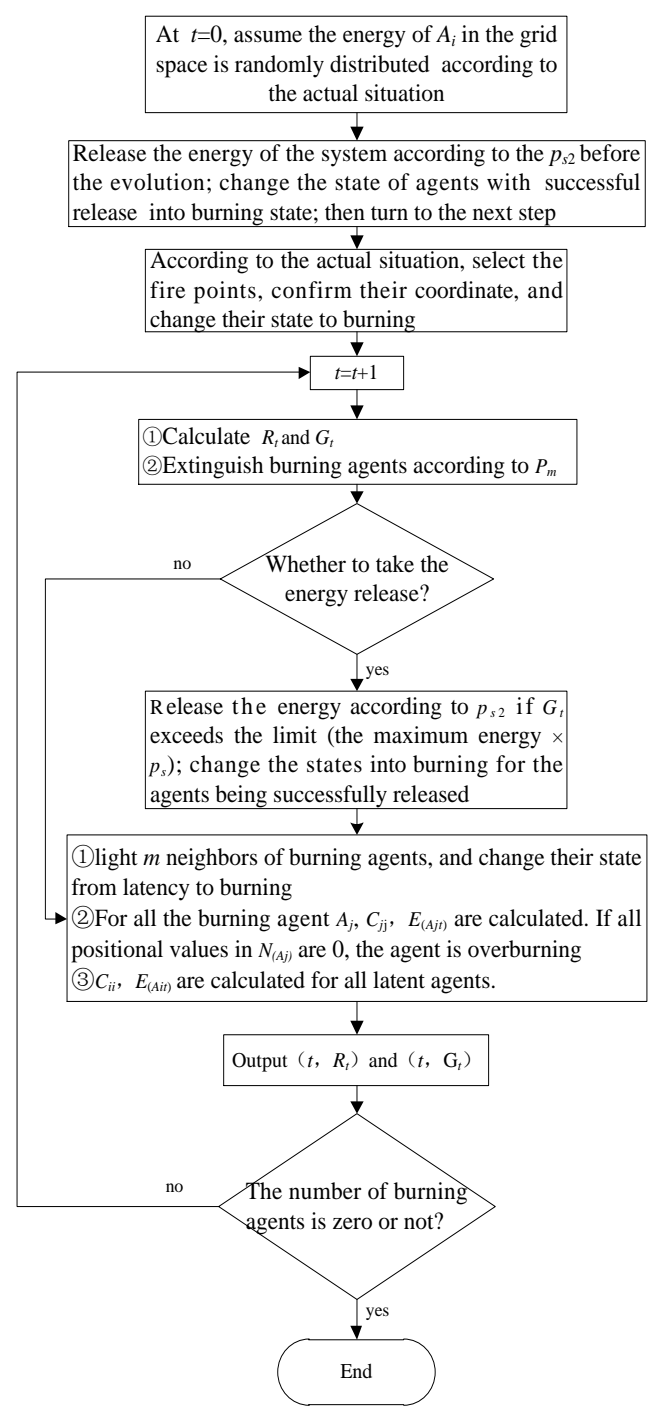

Fig. 1. The computational experimental process 


\section{A. A description of the agents}

The different agents used in this model can be seen in Table 3.

TABLE III. THE AgENTS MAPPING TABLE OF THE Forest Fire System AND THE MODEL SYSTEM

\begin{tabular}{|c|c|c|c|}
\hline $\begin{array}{l}\text { Forest fire } \\
\text { system }\end{array}$ & $\begin{array}{l}\text { Simulation } \\
\text { system }\end{array}$ & $\begin{array}{l}\text { Parameter } \\
\text { explanation }\end{array}$ & Interaction \\
\hline $\begin{array}{l}\text { Fire } \\
\text { environment }\end{array}$ & $\begin{array}{l}\text { Environment } \\
\text { agent }\end{array}$ & $\begin{array}{l}\text { Systematic space } M, \\
\text { systematic original } \\
\text { state, agent } \\
\text { neighbors }\end{array}$ & $\begin{array}{l}\text { Providing space } \\
\text { for agents to } \\
\text { interact }\end{array}$ \\
\hline $\begin{array}{l}\text { Combustible } \\
\text { trees per unit }\end{array}$ & Agent $A_{i}$ & $\begin{array}{l}\text { Evolution state }_{(\mathrm{A})}, \\
\text { evolution period } \\
N_{(\mathrm{A})}, \text { energy } E_{(\mathrm{A})}, \\
\text { latent period } q \text {, the } \\
\text { total burning time, } \\
\text { the length } L_{(\mathrm{A})} \text { of } \\
\text { gene } N_{(\mathrm{A})} .\end{array}$ & $\begin{array}{l}\text { Spreading speed } \\
m \text { and the } \\
\text { efficiency of the } \\
\text { fire } \\
\text { extinguishing } p_{m}\end{array}$ \\
\hline $\begin{array}{l}\text { Supervising } \\
\text { institution }\end{array}$ & $\begin{array}{l}\text { Observer } \\
\text { agent }\end{array}$ & $\begin{array}{l}\text { A systematic } \\
\text { combustion } \\
\text { value(the total of the } \\
\text { burning agents) } \\
\text { curve, a systematic } \\
\text { energy curve, a } \\
\text { control panel }\end{array}$ & $\begin{array}{l}\text { Display of } \\
\text { observed } \\
\text { numbers, control } \\
\text { of systematic } \\
\text { speed }\end{array}$ \\
\hline $\begin{array}{l}\text { Evolution of } \\
\text { the forest fire }\end{array}$ & Model agent & $\begin{array}{l}\text { Evolution rule }\left(C_{i i},\right. \\
\left.C_{j j}\right) \text { of latent agent } A_{i} \\
\text { and burning agent } \\
A_{j}, \text { systematic } \\
\text { evolution period, } \\
\text { systematic burning } \\
\text { number, systematic } \\
\text { total energy }\end{array}$ & $\begin{array}{l}\text { Interaction } \\
\text { model of agents, } \\
\text { model of } \\
\text { accumulated } \\
\text { energy, } \\
\text { observed model } \\
\text { of burning } \\
\text { number }\end{array}$ \\
\hline
\end{tabular}

Subsequently, the simulation algorithm follows the rules of the systematic evolution in this model. In this way the CA itself will transfer energy to simulate the process of the outbreak of a fire.

Assume that $A_{i}$ not only transfers energy but can also be transferred. Thus the adjacent agents' energy in the process of being transferred is gradually activated; moreover the total energy of the system would also gradually accumulate. $A_{i}$ represents the affected unit of the forest, as described in Table 4.

TABLE IV. A COMPARISON OF THE AFFECTED UNIT AND THE AGENT

\begin{tabular}{|l|l|l|l|}
\hline & State & $\begin{array}{l}\text { The period of } \\
\text { evolution }\end{array}$ & Interactions \\
\hline Agent $A_{i}$ & $\begin{array}{l}\text { The state of } \\
\text { the agent }\end{array}$ & Length of gene & $\begin{array}{l}\text { Burning agents are } \\
\text { transitive. The latent } \\
\text { agents' energy accumulates } \\
\text { every cycle automatically }\end{array}$ \\
\hline $\begin{array}{l}\text { The } \\
\text { affected } \\
\text { unit }\end{array}$ & $\begin{array}{l}\text { Latency, } \\
\text { burning, } \\
\text { extinguishing, } \\
\text { overburning }\end{array}$ & $\begin{array}{l}\text { The maximum } \\
\text { time of the } \\
\text { latency of trees }\end{array}$ & $\begin{array}{l}\text { The burning unit is } \\
\text { transitive, triggering fire in } \\
\text { neighboring forest units }\end{array}$ \\
\hline
\end{tabular}

\section{B. The composition of the system}

Suppose the system is a two-dimensional grid space. The coordinate of agent $A_{i}$ is $\left(x_{i}, y_{i}\right), i=1,2, \ldots, M$, where $M$ is the sum of agents in the system. One and only one $A$ is put into in each grid space unit. The original state $(t=0)$ refers to the fact that several random agents are in a state of burning (or some specific burning points are selected according to the actual situation), but other agents are in a latent state. The energy of agents is distributed randomly or is submitted to a certain distribution pattern according to actual situation.

\section{The state parameter}

$\mathrm{A}_{i}$ is the dynamic subsystem with a certain energy, whose state parameters include gene $N_{(\mathrm{A} i)}$ and the current state $\operatorname{state}_{(\mathrm{A} i) \text {. }}$ $N_{\text {(Ai) }}$ is composed of the binary numbers of a specific length $\left(L_{(\mathrm{A})}\right)$. Its positional value 0 and 1 indicate the stability and disorder respectively, and the form of $N_{(\mathrm{A} i)}$ is as follows:

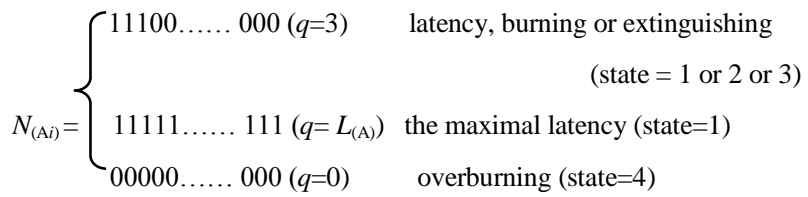

In the formula above, the latent state of agents means that there is a state where energy is accumulating before burning; the agent in an extinguishing or overburning state should discontinue its evolution; and the positional value could be from 1 to 0 , or 0 to 1 . The former change means the agent is burning and the energy is declining; whereas the latter one means the agent is accumulating energy.

\section{The rules of evolution}

1) The energy accumulation and evolution rule

The self-evolution rule of all latent agents is that the number of 1 in $N_{(\mathrm{A} i)}$ adds $k$ until all the position values are changed into 1 .

$$
C_{i i}=k \text { positions change from } 0 \text { to } 1 \text { to the right in } N_{(\mathrm{A} i)} \text {, }
$$

$$
\text { if } \operatorname{state}_{(\mathrm{A} i)}=1
$$

\section{2) Lighting rule}

Burning agents could lead to their $m$ latent neighbors catching fire. Furthermore, the state of the agents catching fire could change from latency to burning. The value of $m$ is decided by the speed of fire spreading; the faster the fire spreads, the higher the $m$ is.

\section{3) Self-evolution rule}

The self-evolution rule of $A_{j}$ in a burning state is as follows: the number of 1 in $N_{(A j)}$ subtracts $k_{2}$ until all positional values are 0 . Then the state could be changed from burning to overburning, in which the state evolution discontinues.

$$
\begin{gathered}
C_{j j}=k_{2} \text { positions change from } 0 \text { to } 1 \text { to the left in } N_{(\mathrm{A} i)}, \\
\text { if state } A_{j}=2
\end{gathered}
$$

\section{E. The efficiency of the fire extinguishing process}

In the $t$-th cycle, the burning agents could be extinguished by the efficiency of the fire extinguishing $p_{m}$; its state changes from burning to extinguished. The agent evolution no longer occurs if the agent has been extinguished. 


\section{$F$. The observing value indicators of the evolution}

At the $t$-th cycle ( $\mathrm{t} \in[0, \mathrm{~T}])$, assume $R_{t}$ is the total of the burning agents, and $G_{t}$ is the cumulative total energy of the system.

For agent $A_{i}$, assume $E_{(A i)}$ is the current energy, which is determined by the number of 1 in $N_{(\mathrm{A} i)}$ at the $t$-th cycle. The formula of $E_{(A i)}$ is shown below.

$E_{\left(A_{i t}\right)}=0.1 \sum_{k=1}^{L_{(A)}} n_{i k}, n_{i k}=0$ or 1

$n_{i k}$ means the positional value in $N_{(\mathrm{A} i)}$; and $L_{(A)}$ is the length of the agent gene $N_{(\mathrm{A})}$. When the state of $A_{i}$ is burnt out, its energy is minimum and therefore zero; when $A_{i}$ is at its maximum latency stage, its energy is the maximum for $0.1 L_{(A)}$.

The total energy of the system at the $t$-th cycle is as follows:

$G_{t}=\sum_{i=1}^{M_{t}} E_{\left(A_{i t}\right)}=0.1 \sum_{i=1}^{M_{t}} \sum_{k=1}^{L_{(A)}} n_{i k}$

$M_{t}$ is the number of agents that have energy at the $t$-th cycle. $M_{t} \leq M$.

\section{THE ENERGY RELEASE ALGORITHM}

A lot of internal energy (including dry leaves, branches, and weeds) has accumulated within the forest system. If the initiative is taken in a planned manner to fell, lop, clean, set fire (and control the size of this fire), the internal energy in the forest system will be effectively released, and there may be no serious forest fires.

Embedded the energy release algorithm in the basic forest fire model, we can analyze its effect on management. If $G_{t}$ and the maximum internal energy meets or exceeds the energy limit value ( the limit ratio is $p_{s}$ ), the system begin to release some energy from the latent and extinguished agents in accordance with probability $p s_{2}$.

The related parameters are shown in Table 5.

TABLE V. THE RELATED PARAMETERS

\begin{tabular}{|l|l|}
\hline parameters & meaning \\
\hline$R_{t}$ & the total number of burning agents \\
\hline$G_{t}$ & the cumulative total energy of the system \\
\hline$p_{m}$ & the efficiency of extinguishing procedures \\
\hline$v$ & the change rate of $p_{m}$ \\
\hline$m$ & the spreading speed \\
\hline$p_{s}$ & the energy limit value ratio \\
\hline$p_{s 2}$ & the energy release ratio \\
\hline
\end{tabular}

\section{A Simulation ANALYSis}

The simulation could be implemented after the model and the related parameters setting are completed. In this section, we analysis four kinds of simulations.

\section{A. Case simulation}

The case simulation takes the huge forest fire in Australia in 2009 as the prototype. This fire lasted for 35 days from February 7, 2009 to the end of March 14, 2009 and led to an area of 410000 hectares being burned. There were three fire points on February 7 th after nearly a month of hot and dry days; furthermore following the outbreak, the local wind speed reached $96 \sim 115 \mathrm{~km} / \mathrm{h}$.

The setting of parameters refers to the case above; assume that it takes one day of actual time for the models to run a cycle, and the system space of model is $M=100 \times 100$. Due to nearly a month of hot and dry days, the amount of energy becomes larger, set $q=26, L_{(A)}=40$, and the maximum energy $=0.1 \times$ $40 \times 10000=40000$. The number of burning points is set up as the actual value $w=3$; and considering that the actual fire spreads quickly, subsequently the spreading speed is set up at a larger value $m=24$. According to a repeated trial, the extinguishing efficiency is set as $p_{m} \in(0,0.5)$, and the change rate $v$ increases by 0.0125 every cycle.

The simulation results are shown in Figure 2.

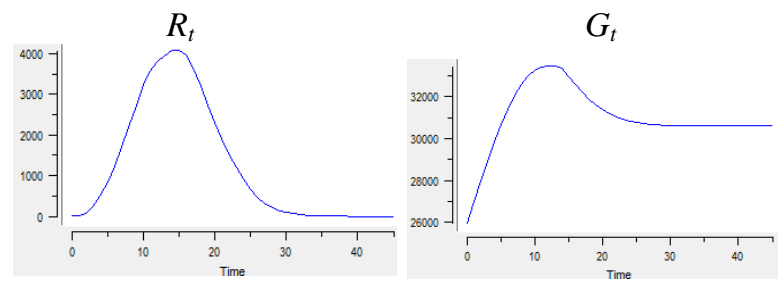

Fig. 2. The simulation results of the Australian large forest fire

The simulation result shows that $R_{t}$ at the explosion point is 4094. If one grid represents 100 hectares, it can be converted into a burned area of $4094 \times 100=40.94$ million hectares, which is quite close to actual 410,000 hectares. Seen from the evolutionary cycle perspective, 39 cycles when $R_{t}$ equals zero is close to the actual duration of the fire, which was 35 days. The model could restore the evolution of the fire to a higher degree.

From an analysis of the energy, it could have been as high as 26,000 at the start point, which takes up $26000 \div 40000$, or $65 \%$ of the maximum energy; additionally the maximum energy in the evolution is up to 32,986 , and 30,614 residual units of energy remained after the fire went out. Excessive energy can eventually lead to the primary cause of a large forest fire's outbreak. Since the remaining energy is higher than the initial energy, it may still lead to large forest fires later on.

\section{B. A simulation for increasing the extinguishing efficiency}

When the efficiency of extinguishing a fire is at a low level, the fire cannot be controlled effectively because of its high spread rate. A series of experiments are completed for increasing the extinguishing efficiency to $v>0.0125$. The evolution results are shown in Figures 3 and 4 when $v=0.02$ and $v=0.1$.

The results of the calculative experiments show that when the rate is up to $\mathrm{v}=0.02, R_{t}$ at the explosion point drops from 4094 to 2194 , which is a decrease of $46.41 \%$. Moreover, the duration of the fire is shortened from 39 to 35 days, which is a decrease of $10.26 \%$. The highest energy of the evolution rose slightly to 35754 , and the remaining energy rose to 33988.1; therefore the residual risk of fire would be higher. 

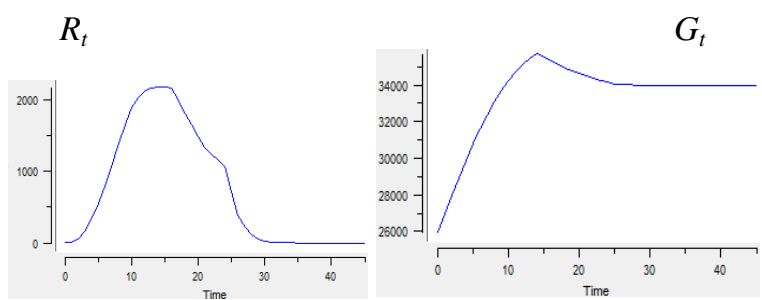

Fig. 3. A higher efficiency for extinguishing the fire $(\mathrm{v}=0.02)$
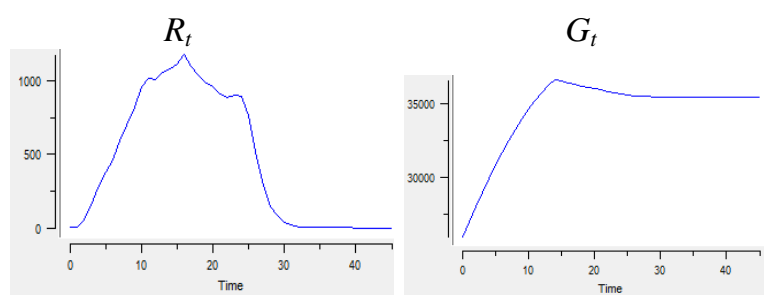

Fig. 4. A higher efficiency for extinguishing the fire $(v=0.1)$

When the efficiency of the fire extinguishing procedures are substantially improved to $\mathrm{v}=0.1, R_{t}$ at the explosion point would drop to 1185 , a decrease of $71.06 \%$, and the duration of fire would increase to 40 days. The highest energy of the evolution continues to rise to 36651.6, and the remaining energy further increases to 35464.3 .

Thus, increasing the efficiency of the fire extinguishing procedures can decrease $R_{t}$ greatly, but has no obvious effect on the duration of fire; and the duration would be extended if the efficiency of the fire extinguishing is excessively improved. Furthermore, increasing the efficiency of the fire extinguishing procedures will increase $G_{t}$ and the remaining energy; this would perhaps increase the follow-up risks.

\section{Reducing the speed of the fire spreading}

A series of experiments are implemented by reducing the speed of the fire spreading when $\mathrm{m}<24$, as another very important factor affecting the size of the fire is its spreading rate. Catastrophic fire is often accompanied by strong winds, resulting in a low efficiency of fire extinguishment, and meaning that the fire cannot be effectively controlled. If the speed of the fire spreading is reduced, the evolution of the results is shown in Figures 5 to 7.

Compared with Figure 2, Figure 5 shows that if $m$ drops slightly from 24 to $20, R_{t}$ at the explosion point also drops. The evolution of the maximum energy value is slightly increased, whereas the overall value differs little. However, the evolution results in Figures 6 and 7 show that if the efficiency of the fire extinguishing procedures remains unchanged, reducing the speed of the fire spreading can effectively reduce $R_{t}$ and increase the duration of the fire. Subsequently both the maximum energy and the energy remaining after the evolution could be increased.

Thus, $R_{t}$ is decreased greatly, which increases the efficiency of the fire extinguishing procedures; however it has no obvious effect on the duration of the fire, which would be extended if it was excessively improved. Therefore improving the efficiency of the fire extinguishing procedures would increase $G_{t}$ and the remaining energy, but this might increase the follow-up risks.
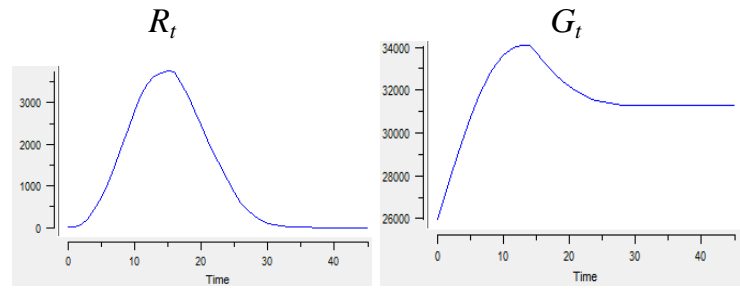

Fig. 5. Reducing the fire spreading speed $(\mathrm{m}=20)$
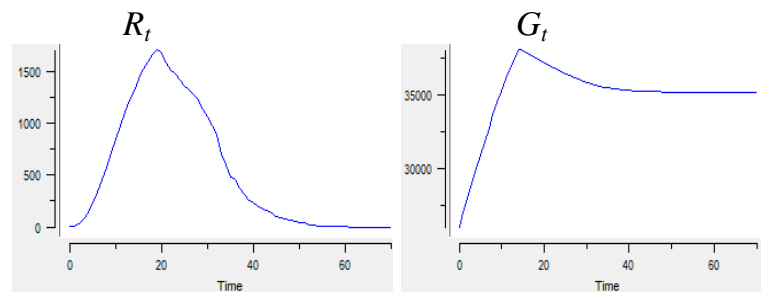

Fig. 6. Reducing the fire spreading speed $(m=8)$
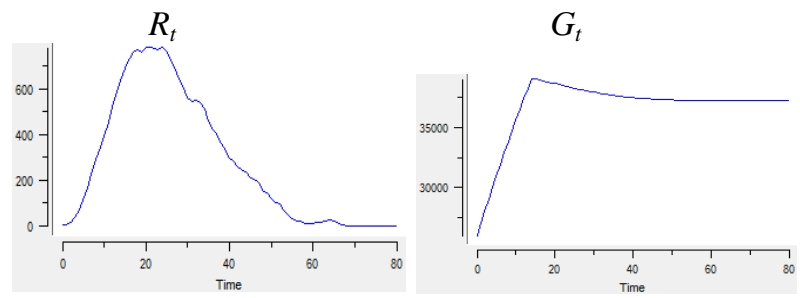

Fig. 7. Reducing the fire spreading speed $(m=4)$

\section{The energy release model}

The release of energy can be implemented before the forest fire occurs. Relevant activities would include as cutting down or pruning the trees that are too dense and clearing up the withered branches. Related measures may also be implemented after the fire, such as cutting down part of the forest zone which has not been affected by the fire to set up an isolation strip so as to control the fire.

\section{1) Release the energy before the evolution}

If the releasing ratio is $10 \%$, it is known from figure 2 that the initial energy is $26000 \times(1-10 \%)=23400$, and $58.5 \%$ $(23400 \div 40000)$ of the maximum energy. The results of this evolution are shown in Figure 8.
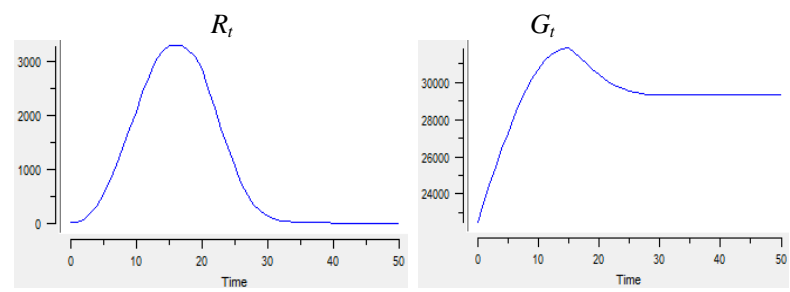

Fig. 8. Releasing $10 \%$ of the energy

Results show that $R_{t}$ at the explosion point drops from 4094 to 3288 , thereby reducing by $19.69 \%$; moreover the fire duration is slightly extended from 39 days to 40 days.

If a huge amount of energy is released, the releasing ratio is set for $40 \%$. Then the initial energy is $26000 \times(1-40 \%)=$ 15600 , and $39 \%(15600 \div 40000)$ of the maximum energy. The results of this evolution are shown in Figure 9. 

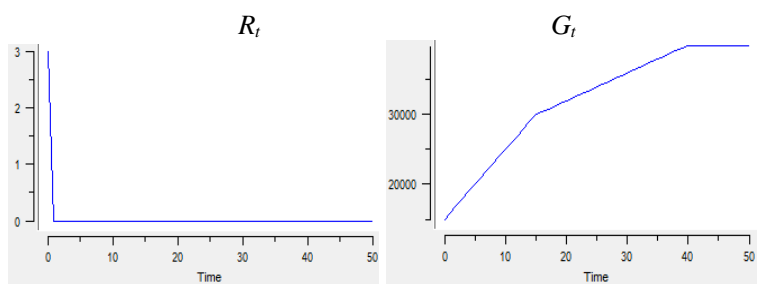

Fig. 9. Releasing $40 \%$ of the energy

From the calculation results in Figure 9, there is no outbreak of fire, and the $R_{t}$ set at the first cycle quickly changes from three to zero. Additionally, after a series of computational experiments, the energy of the pre-release ratio is less than $40 \%$, which could lead to a fire. When the ratio is $39 \%$, the results of the evolution are shown in Figure 10.
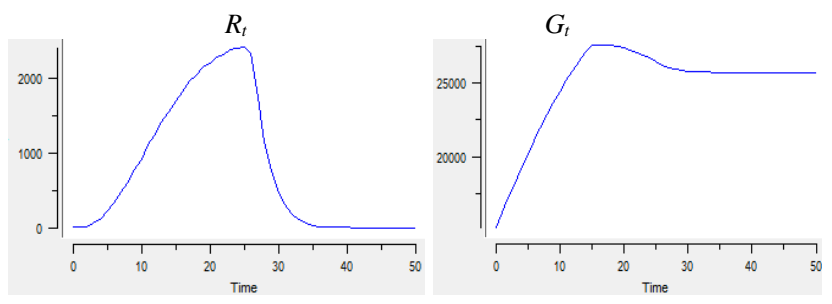

Fig. 10. Releasing 39\% of the energy

When the releasing ratio is $39 \%, R_{t}$ at the explosion point drops from 4094 to 2429 , a reduction of $19.69 \%$; moreover the fire duration is slightly extended from 39 days to 40 days.

The above experiments show that the higher the proportions of energy released before the evolution, the more obvious the result.

2) Release the energy during the evolution

In this case the initial energy is as high as 26,000, accounting for $65 \%(26000 \div 40000)$ of the maximum energy. In order to control the fire effectively, the energy must be first released. Because $p_{s}$ can only decide when to terminate the release and to re-release the energy, it cannot be too small; furthermore $p_{s 2}$ is the energy ratio for each release, and it cannot be too large. Thus $p_{s} \in[0.4,0.65], p_{s 2} \in[0.1,0.5]$ is set for a series of experiments. Some of the experimental results are shown in Figures 11 to 16; whereas all of the results are shown in Table 6.
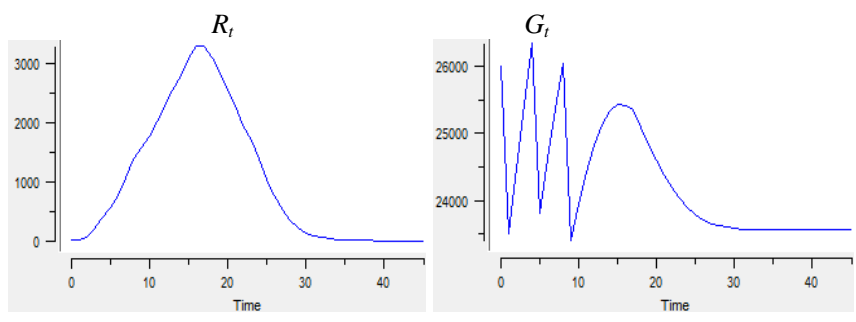

Fig. 11. Releasing the energy (ps $=0.65$, ps $2=0.1$ )

$R_{t}$

$G_{t}$
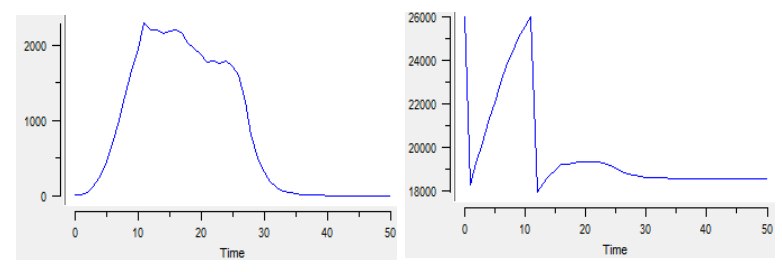

Fig. 12. Releasing the energy ( $\mathrm{ps}=0.65$, ps $2=0.31$ )
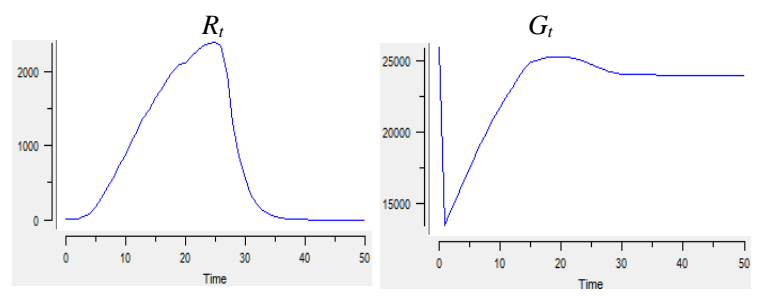

Fig. 13. Releasing the energy (ps $=0.65$, ps $2=0.5$ )
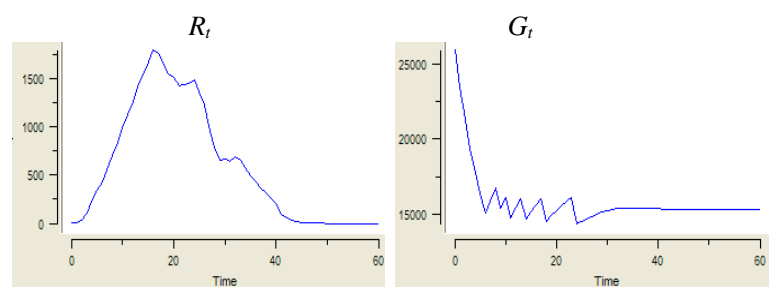

Fig. 14. Releasing the energy (ps $=0.4, p s 2=0.1)$
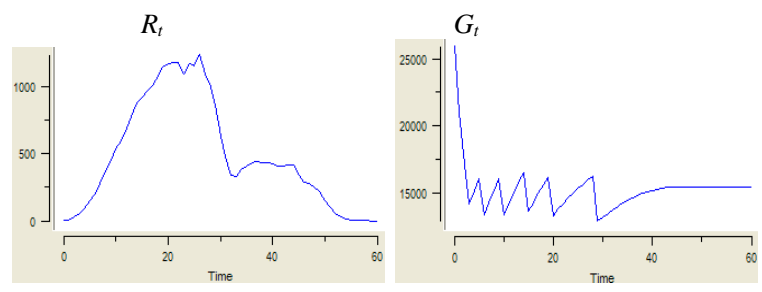

Fig. 15. Releasing the energy (ps $=0.4, p s 2=0.2)$
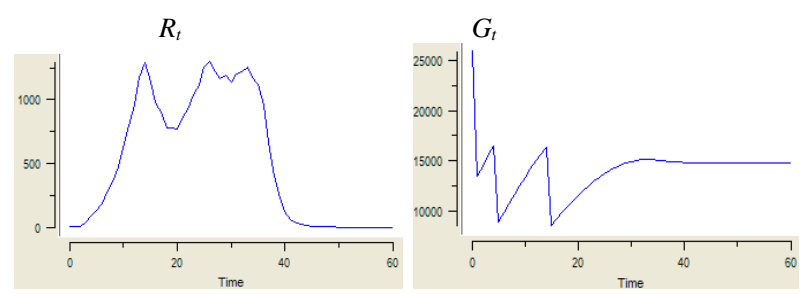

Fig. 16. Releasing the energy ( $\mathrm{ps}=0.4$, ps $2=0.5$ )

The aforementioned series of computational results show that when the ratio of energy limitation reaches a higher point $\left(p_{s}=0.65\right)$, the best value of the probability of the energy release is $p_{s 2}=0.31$, and $R_{t}$ at the explosion point decreases from 4094 to 2303 , which is a decrease of $43.75 \%$. When the ratio of energy limitation reaches a lower point $\left(p_{s}=0.4\right)$, the best value of the probability of the energy release is $p_{s 2}=0.2$, and $R_{t}$ at the explosion point decreases from 4094 to 1177, which is a decrease of $71.25 \%$. Therefore a lower ratio of energy limitation value could lead to more effective management. 
TABLE VI. THE EFFECT COMPARISON OF THE ENERGY RELEASE

\begin{tabular}{|l|l|l|c|}
\hline $\boldsymbol{p}_{s}$ & \multicolumn{1}{|c|}{$\boldsymbol{p}_{\mathbf{s} 2}$} & $\begin{array}{l}R_{t} \text { at the explosion point } \\
\text { and the decrease ratio }\end{array}$ & $\begin{array}{l}\text { The duration of } \\
\text { the evolution }\end{array}$ \\
\hline 0.65 & 0.1 & $3298,19.44 \%$ & 39 cycles \\
\hline 0.65 & 0.2 & $2890,29.41 \%$ & 44 cycles \\
\hline 0.65 & 0.3 & $2312,43.53 \%$ & 41 cycles \\
\hline 0.65 & 0.31 (the best) & $2303,43.75 \%$ & 40 cycles \\
\hline 0.65 & 0.4 & $2949,27.97 \%$ & 39 cycles \\
\hline 0.65 & 0.5 & $2398,41.43 \%$ & 41 cycles \\
\hline 0.4 & 0.1 & $1804,55.94 \%$ & 50 cycles \\
\hline 0.4 & 0.2 (the best) & $1177,71.25 \%$ & 59 cycles \\
\hline 0.4 & 0.3 & $1209(943), 70.47 \%$ & 70 cycles \\
\hline 0.4 & 0.4 & $1439(776), 64.85 \%$ & 78 cycles \\
\hline 0.4 & 0.5 & $\begin{array}{l}1291(1304,1258), \\
68.15 \%\end{array}$ & 50 cycles \\
\hline 3$)$ & & &
\end{tabular}

3) Release the energy before the evolution and during the evolution

If the energy is released before the evolution, the energy is set to drop from 26,000 to 20,000 (that is $23.08 \%$ of the energy is released), which accounts for $50 \%$ of the maximal energy.

Then, the energy release is implemented during the evolution. A series of experiments are performed by selecting $p_{s}=0.4, p_{s 2} \in[0.1,0.5]$. Some of the experimental results are shown in Figures 17 to 19, and the effects of the experiment are shown in Table 7.

The aforementioned series of computational results show that when the ratio of the energy limit reaches a lower point $\left(p_{s}\right.$ $=0.4$ ), the probability of energy release, $p_{s 2}$, reaches 0.16 , and $R_{t}$ at the explosion point decreases rapidly from the three that was initially set to zero after six cycles; this makes it possible to completely control the fire. Thus the effect of the energy release before and during the fire is very distinct.

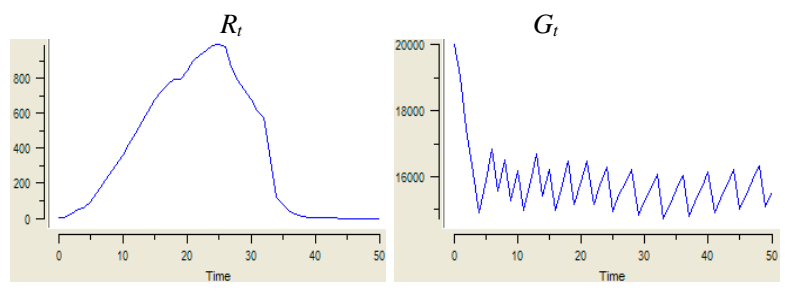

Fig. 17. Releasing the energy (ps $=0.4, \mathrm{ps} 2=0.1$ )
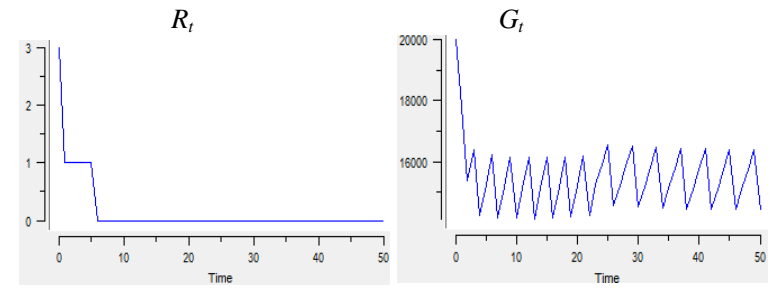

Fig. 18. Releasing the energy (ps $=0.4$, ps $2=0.16$ )
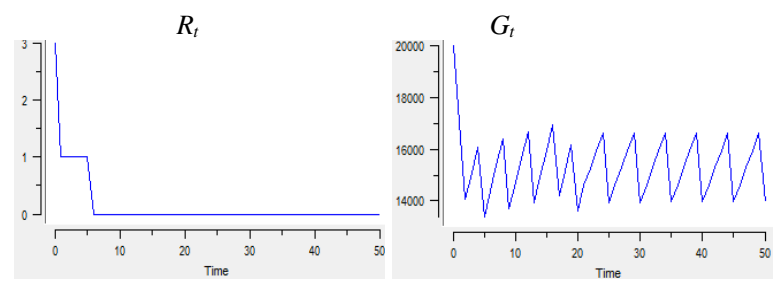

Fig. 19. Releasing the energy (ps $=0.4, \mathrm{ps} 2=0.5$ )

TABLE VII. THE EFFECT COMPARISON OF THE ENERGY RELEASE

\begin{tabular}{|c|c|c|c|}
\hline $\boldsymbol{p}_{\boldsymbol{s}}$ & $\boldsymbol{p}_{\mathrm{s} 2}$ & $\begin{array}{l}R_{t} \text { at the explosion } \\
\text { point }\end{array}$ & $\begin{array}{l}\text { The duration of the } \\
\text { evolution }\end{array}$ \\
\hline 0.4 & 0.1 & 999 & 44 cycles \\
\hline 0.4 & 0.16 & 3 & 6 cycles \\
\hline 0.4 & 0.2 & 3 & 6 cycles \\
\hline 0.4 & 0.3 & 3 & 6 cycles \\
\hline 0.4 & 0.4 & 3 & 6 cycles \\
\hline 0.4 & 0.5 & 3 & 6 cycles \\
\hline
\end{tabular}

VI. CONCLUSIONS

The experiments have shown that the model proposed in this paper is suitable for analyzing the internal factors of the forest fire evolution and fires management practices. In order to control a fire, a scientific release of the energy could be considered to take. In addition, increasing the extinguishing efficiency and reducing the spread of the fire actually has an adverse effect on the management of the fire.

Following the simulations carried out in this paper, a number of suggestions can be proposed:

1) The method of releasing energy in a small scale before and during the disaster is scientific and feasible, and it can reduce the number of forest fires. It is crucial to scientifically determine the energy release time, energy limit value ratio $p_{s}$ and the probability of the energy release $p_{s 2}$; moreover it is necessary to find the most feasible solution in this area.

2) Improving the efficiency of the fire extinguishing procedures is the most direct and effective way to control forest fires. However, once a large-scale forest fire has broken out, it is hard to improve the firefighting efficiency and achieve better results. In addition, fire-fighting efficiency is a double-edged sword. The higher the efficiency, the smaller the burned area; however this leads to a larger residual energy, which may increase the risk of subsequent fires.

3) Reducing the speed of the fire spreading is another effective method. A significant reduction in the speed of the fire spreading can effectively reduce $R_{t}$ at the explosion point (burned area). However, the fire spreading speed depends on the wind speed, wind direction, temperature, fuels, obstacles and other factors, which are generally difficult to control.

However, some factors of the forest fires, such as geologic structure, are rarely considered in this paper. And the action moment of the energy release need further research. 


\section{ACKNOWLEDGMENT}

The This work was supported in part by the Chinese National Natural Science Foundation (No. 71371148); China postdoctoral Fund Projects (No. 2013M542080); China postdoctoral Fund Special projects (No.2014T70750) and Hubei province: humanities and social science project(No. 14G524).

\section{REFERENCES}

[1] S. Clar, B. Drossel, K. Schenk, F. Schwabl, "Self-organized criticality in forest-fire models," Physica A: Statistical Mechanics and its Applications, vol. 266, pp. 153-159, April 1999.

[2] B. Drossel, F. Schwabl, "Forest fire model with immune trees," Physica A, vol. 199, pp. 183-197, October 1993.

[3] Guisoni, Nara, Loscar, S. Ernesto, Albano, V. Ezequiel, "Phase diagram and critical behavior of a forest-fire model in a gradient of immunityGuisoni," Physical Review E - Statistical, Nonlinear, and Soft Matter Physics, vol. 83, pp. 1-9, January 2011.

[4] S. Yassemi, S. Dragićević, M. Schmidt, "Design and implementation of an integrated GIS-based cellular automata model to characterize forest fire behaviour," Ecological Modelling, vol. 210, pp. 71-84, January 2008.

[5] Thomas J. Duff, Derek M. Chong, Kevin G. Tolhurst, "Using Discrete Event Simulation Cellular Automata models to determine multi-mode travel times and routes of terrestrial suppression resources to wildland fires," European Journal of Operational Research, In Press, Accepted Manuscript.
[6] D.I. Iudin, Ya.D. Sergeyev, M. Hayakawa, "Infinity computations in cellular automaton forest-fire model," Communications in Nonlinear Science and Numerical Simulation, vol. 20, pp. 861-870, March 2015.

[7] L. Herna'ndez Encinas, S. Hoya White, A. Martı'n del Rey, G. Rodri'guez Sa'nchez, "Modeling forest fire spread using hexagonal cellular automata," Applied Mathematical Modelling, vol. 31, pp. 12131227, June 2007.

[8] S. Yassemi, S. Dragićević, M. Schmidt, "Design and implementation of an integrated GIS-based cellular automata model to characterize forest fire behaviour," Ecological Modelling, vol. 210, pp. 71-84, January 2008.

[9] Stephen G Berjak, John W Hearne, "An improved cellular automaton model for simulating fire in a spatially heterogeneous Savanna system," Ecological Modelling, vol. 148, pp. 133-151, February 2002.

[10] A. Alexandridis, D. Vakalis, C.I. Siettos, G.V. Bafas, "A cellular automata model for forest fire spread prediction: The case of the wildfire that swept through Spetses Island in 1990," Applied Mathematics and Computation, vol. 204, pp. 191-201, October 2008.

[11] Z. Hui, W. Tao, W. Daimu, "Polymorphism forest fire probability cellular automata model and its application," Journal of FuYang normal college (Natural Sciences), vol. 27, pp. 23-26, January 2010.

[12] Z. Guangjun, L. Yaodong, "Forest fire system modeling and simulation based on Agent," Computer Engineering Design, vol. 31, pp. 44514454, October 2010.

[13] Z. Guiqing, Y. Zi, W. Lin, Z. Kaien, C. Tianlun, "Self Organized Criticality in a Simple Forest Fire Model," Journal of Nankai University (Natural Sciences), vol. 44, pp. 76-81, October 2011. 